\section{Nasale Steroide schützen vor Asthma}

\author{
Asthma bronchiale geht nicht selten mit einer allergischen Rhinitis \\ oder einer Sinusitis einher. Diese Erkrankungen werden in der Regel \\ unabhängig von der Asthmamedikation behandelt. Eine Studie \\ untersuchte, ob sich eine antientzündliche Therapie der Nase auf \\ die Asthmasymptomatik auswirkt.
}

m Rahmen einer retrospektiven Kohortenstudie wurden die Daten von neu diagnostizierten Asthmapatienten einer Managed-Care-Organisation gesammelt und über einen Zeitraum von drei Jahren auf Notfalleinweisungen ins Krankenhaus aufgrund eines Asthmaanfalls überprüft. Außerdem wurden die Asthmamedikation und das Vorliegen nasaler Begleiterkrankungen und deren Behandlung erfasst.

Von den insgesamt 13.844 dokumentierten Patienten war es bei 1.031 zu einer Notfalleinweisung gekommen. Nahmen die Patienten zusätzlich zur
Asthmamedikation nasale Steroide, reduzierte sich das relative Risiko (RR) einer Einweisung auf 0,7 (95\%-Konfidenzintervall 0,59-0,94). Dieser Wert ergab sich nach Adjustierung u. a. hinsichtlich der Häufigkeit und Art der Asthmatherapie, der ambulanten Versorgung und der nasalen Begleitdiagnose (Rhinitis, Sinusitis oder Otitis media). Der protektive Effekt der nasalen Steroide stellte sich sowohl bei regelmäßiger Anwendung als auch bei nur gelegentlicher Medikation ein. Für die Einnahme von oralen Antihistaminika lag das relative Risiko bei 0,9 (95\%-Konfi-

\title{
Allergiegeschehen nur auf lokaler Ebene
}

\section{Bei Patienten mit einer durch Provokationstests nachgewiesenen Nahrungsmittelunverträglichkeit findet man manchmal keine Befunde für eine IgE-vermittelte Reaktion im Serum oder im Haut- Pricktest. Trotzdem kann die Reaktion allergisch bedingt sein, das Geschehen spielt sich in solchen Fällen offenbar lokal begrenzt $a b$.}

$\mathrm{U}$ m allergischen Lokalreaktionen auf die Spur zu kommen, untersuchte eine schwedische Forschergruppe $14 \mathrm{~Pa}$ tienten mit einer durch einen doppelblinden, plazebokontrollierten Nahrungsmittelprovokationstest verifizier-

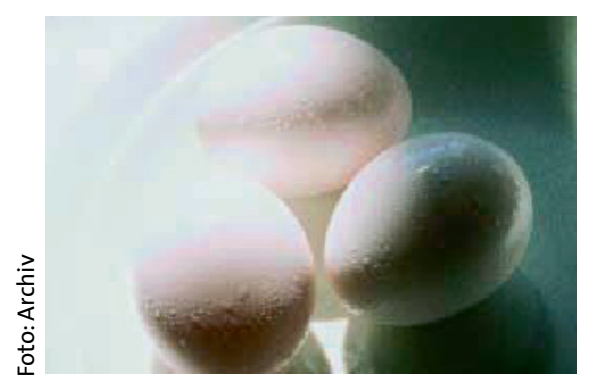

Allergisch gegen Hühnereier und trotzdem kein spezifisches IgE im Serum? ten Nahrungsmittelunverträglichkeit. Bei elf von ihnen fanden sich weder im Hauttest noch im Serum Hinweise auf spezifische IgE-Antikörper. Nach einer offenen Nahrungsmittelprovokation sowie in einer asymptomatischen Phase zwei bis drei Monate nach der Provokation wurden den Patienten Dünndarmbiopsien entnommen und diese auf das Vorliegen verschiedener Immunzellen hin untersucht. Als Kontrollgruppe dienten gesunde, von Alter und Geschlecht her passende Probanden.

In der symptomatischen Phase fand sich bei den Patienten eine signifikant erhöhte Anzahl von $\mathrm{MBP}^{+}$-Eosinophilen (MBP: Major Basic Protein), IgEtragenden Zellen und T-Zellen $\left(\mathrm{CD}^{+}\right.$, denzintervall 0,78-1,11). Wie dieser Schutzeffekt der nasalen Steroide zu erklären ist, bleibt noch unklar. Ein direkter Einfluss der nasalen Steroide auf das Bronchialsystem kann aber aufgrund der minimalen Deposition ausgeschlossen werden. Vielmehr deuten die Befunde darauf hin, dass die nasale Entzündung ein wichtiger Einflussfaktor für die erhöhte Reagibilität der unteren Atemwege ist - ein schon in anderen Studien festgestellter Zusammenhang.

Fazit: Asthmapatienten mit allergischen Erkrankungen der Nase profitieren von einer zusätzlichen Therapie der nasalen Symptome, vor allem in Form eines nasalen Steroids. Die Minderung der Entzündungsvorgänge in der Nasenschleimhaut scheint sich auf die unteren Atemwege positiv auszuwirken. $\quad b k$

Adams RJ et al. Intranasal steroids and the risk of emergency department visits for asthma. J Allergy Clin Immunol 2002; 109: 636-42

$\mathrm{CD}^{+}, \mathrm{CD}^{+}$) im Vergleich $\mathrm{zu}$ den asymptomatischen Zeiten, bzw. im Vergleich zu den Kontrollpersonen. Die Zahl der Entzündungszellen korrelierte mit der Schwere der Symptome. Auch war unmittelbar nach der Provokation die Zahl der IL-4 $4^{+}$-Zellen erhöht und die der IFN- $\gamma^{+}$-Zellen erniedrigt. Unterschiede im Gesamt-Serum-IgE fanden sich zwischen den Gruppen nicht. Die Befunde zeigen, dass als Reaktion auf Nahrungsmittelantigene Entzündungszellen in die Darmmukosa einwandern, dort die allergische Kaskade in Gang setzen und damit die klinische Symptomatik hervorrufen können.

Fazit: Bei Patienten mit einer Nahrungsmittelallergie sind manchmal keine IgE-Antikörper im Serum oder in der Haut nachzuweisen. Bei ihnen werden die Symptome offensichtlich durch eine lokale, IgE-vermittelte Immunantwort auf die Nahrungsmittelallergene hervorgerufen.

Lin XP et al. Local allergic reaction in food-hypersensitive adults despite a lack of systemic food-specific IgE. J Allergy Clin Immunol 2002; 109: 879-87 